УДК 631.5

DOI: 10.36461/NP.2019.52.3.012

\title{
ТЕХНИКО-ТЕХНОЛОГИЧЕСКОЕ ПРИМЕНЕНИЕ ЖИДКИХ АЗОТНЫХ \\ И АЗОТО-СЕРОСОДЕРЖАЩИХ УДОБРЕНИЙ НА БАЗЕ КАС-32 В ПОСЕВАХ ЗЕРНОВЫХ И ЗЕРНОБОБОВЫХ КУЛЬТУР
}

В. А. Милюткин, доктор техн. наук, професссор,

А. М. Петров, канд. техн. наук, профрессор

Федеральное государственное бюджетное образовательное учреждение

высшего образования «Самарский государственный аграрный университет», Россия, т. 8-927-264-41-88, e-mail: oiapp@mail. ru

О. Н. Кухарев, доктор техн. наук, профрессор

Федеральное государственное бюджетное образовательное учреждение высшего образования «Пензенский государственный аграрный университет, Россия,

т. 8-927-784-79-11, e-mail: rectorat@pgau.ru

Н. Г. Длужевский, инженер-технолог, зам. директора

Публичное акционерное общество «КуйбышевАзот», т. 8-927-784-79-11, e-mail: svrp2@mail. ru

В работе представлены материалы лабораторно-полевых исследований Самарского ГАУ по изучению эффективности жидких минеральных азотных и новых азотосеросодержащих удобрений на базе КАС-32 по сравнению с твердыми - аммиачная селитра, производимых ПАО «КуйбышевАзот» (г. Тольятти, Самарская обл.) при возделывании зерновых (твердая пшеница) и зернобобовых (соя) по технологии MINI-TILL, обеспечиваемой сельскохозяйственным машинным комплексом АO «Евротехника» (г. Самара) немецкой компании «AMAZONEN-Werke» (Германия). Цель работы: определение эффрективности азотных жидких минеральных удобрений производства ПАО «КуйбышевАзот» и новых азото-серосодержащих в сравнении с традиционными твердыми минеральными удобрениями - аммиачная селитра - с определением оптимальных доз, способов и времени внесения, необходимых технических средств на различных сельхозкультурах, в том числе на зерновых и зернобобовых. В засушливый 2018 год (седьмой год по засухе с 1936 года) были получены достаточно высокие результаты по урожайности и качеству произведенной продукции при применении КАС-32, КАС-32 с серой и РПС (раствор питательный серосодержащий) в сравнении с твердыми минеральными удобрениями (аммиачная селитра) при их внесении опрыскивателями АО «Евротехника», оборудованными крупнокапельными распылителями и шлангами удлинителями для листовой и внекорневой (прикорневой) подкормки растений.

Ключевые слова: техника, технологии, «MINI-TILL», удобрения, жидкие, твердые, внесение, подкормка, урожай, качество, зерновые, зернобобовые.

\section{Введение}

Поставленные агропромышленному комплексу руководством страны задачи по обеспечению собственных потребностей в сельскохозяйственной продукции и значительному увеличению ее поставок на экспорт, причем с высоким качеством, требуют от работников АПК и аграрной науки интенсивного внедрения высокоэффрективных новейших энерго-ресурсосберегающих технологий [1-7, 9], сельхозмашин, семян, удобрений, средств защиты и т. д. Самарский государственный аграрный университет совместно с ведущим в России сель- хозмашиностроительным предприятием по прицепной технике $\mathrm{AO}$ «Евротехника» (г. Самара) немецкой компании «AMAZONENWerke» и крупнейшим заводом по производству минеральных удобрений ПАО «КуйбышевАзот», региональными сельскохозяйственными НИИ селекции и семеноводства в г. Самара проводит широкие исследования по повышению эффективности производства сельскохозяйственной продукции. Данный материал представляет актуальные результаты деятельности в данном направлении на зерновых и зернобобовых культурах. 


\section{Методы и материалы}

Жидкие удобрения КАС-32, КАС-32 с содержанием серы и раствор питательный серосодержащий (РПС) производства ПАО «КуйбышевАзот» в 2018 г. испытывались на полевых и производственных опытах МИП «Агроакадемия» Самарская обл., Кинельский район, п. Угорье. Почва экспериментального участка - чернозем обыкновенный остаточно-карбонатный, среднемощный, тяжелосуглинистый с содержанием легкогидролизуемого азота 124 мг, подвижного фосфрора 143 мг и обменного калия 310 мг на кг почвы, pH 6,2. Система обработки почвы - минимальная, дисковыми боронами и культиваторами АО «Евротехника» немецкой сельскохозяйственной машиностроительной компании «АМАZONEN-Werke».

В связи с тем, что в исследованиях использовались серосодержащие минеральные удобрения (КАС-32 + S) и КАС-32 + РПС, перед исследованиями и в их процессе, в почве и в вегетативных частях растений возделываемых сельскохозяйственных культур определялась сера - S (мг / кг почвы), а также показатель кислотности $\mathrm{pH}$ и качественные показатели произведенной продукции. Сложившийся летний сезон в 2018 году характеризовался как острозасушливый и жаркий, по сравнению со среднемноголетними данными: за апрель - октябрь месяцы выпало осадков 223,3 мм, что составило $72 \%$ от среднемноголетних (308,6 мм). Особенно десрицитными по осадкам были месяцы: май $(59,8 \%)$, июнь $(34,2 \%)$, август $(30,2 \%)$, сентябрь $(41,7 \%)$ и октябрь $(47,6 \%)$ на фоне превышающих среднемноголетние показатели в апреле (166,9\%) и июле $(144,8 \%)$. В целом по Самарской области по дефициту влаги 2018 год отнесен на седьмое место с 1936 года.

В соответствии с программой исследований заложены два полевых опыта.

І. Опыт применения жидких минеральных удобрений при возделывании яровой твердой пшеницы сорта Марина селекции Самарского НИИСХ на опытных полях Самарского ГАУ. Срок посева 22.05.2018 г.; норма высева - 4,0 млн. всхожих зерен /га.

Варианты опыта:

1. Внесение аммиачной селитры под предпосевную культивацию в дозе 176 кг/га $\left(\mathrm{N}_{60}\right.$ кг д. в./га) разбрасывателем минеральных удобрений ZA-M 1500 (AMAZONE) (производственный контроль).

2. Одноразовое сплошное внесение KAC-32 опрыскивателем UR 3000 крупнокапельными семи струйными форсунками под предпосевную культивацию 144 л/га (N60 кг д. в./га).

3. Одноразовое сплошное внесение под предпосевную культивацию опрыскивателем UR 3000 (AMAZONE) крупнокапельными семи струйными форсунками КАС-32 + S - 134 л/га (N40 кг д. в./га + S5 кг д. в./гa).

4. Внесение КАС-32 + РПС (раствор питательный серосодержащий):

a) Внесение опрыскивателем UR 3000 (AMAZONE) крупнокапельными семи струйными форсунками под предпосевную культивацию КАС-32 - 96 л/га ( $\mathrm{N}_{40}$ кг д. в./га);

б) Подкормка в фазу 8-10 листьев опрыскивателем UR 3000 (AMAZONE) удлинительными шлангами РПС (раствор питательный серосодержащий) 200 л/га ( $\mathrm{N}_{20}$ кг д. в./га $+\mathrm{S}_{23}$ д. в. кг/га).

5. Без удобрений (абсолютный контроль).

II. Опыт применения жидких минеральных удобрений при возделывании сои сорта Волма.

Варианты опыта:

1. Внесение аммиачной селитры разбрасывателем ZA-M 1500 под предпосевную культивацию 220 кг/га (N75 кг д. в./га) (производственный контроль);

2. Внесение КАС-32 опрыскивателем UR 3000 (AMAZONE) крупнокапельными семи струйными форсунками 170 л/га (N75 кг д. в./га) под предпосевную культивацию;

3. Дробное внесение КАС-32:

a) Сплошное внесение под предпосевную культивацию опрыскивателем UR 3000 (AMAZONE) крупнокапельными семи струйными форсунками 72 л/га ( $\mathrm{N}_{30}$ кг д. в./га);

б) Подкормка в фразе третьего листа опрыскивателем UR 3000 (AMAZONE) удлинительными шлангами в междурядья 72 л/га $\left(\mathrm{N}_{30}\right.$ кг д. в./га);

в) Подкормка в фразе бутонизации опрыскивателем UR3000 удлинительными шлангами в междурядья 36 л/га ( $\mathrm{N}_{15}$ кг д. в./га),

4. Сплошное внесение КАС-32 + S 210 л/га ( $\mathrm{N}_{75}$ кг д. в./га и $\mathrm{S}_{7}$ кг д. в./га) опрыскивателем UR 3000 (AMAZONE) крупнокапельными семи струйными форсунками под предпосевную культивацию.

5. Внесение КАС-32 + РПС (раствор питательный серосодержащий):

а) Сплошное внесение КАС - $32-120$ л/га ( $\mathrm{N}_{50}$ кг д. в./га) опрыскивателем UR 3000 (AMAZONE) крупнокапельными семи струйными форсунками под предпосевную культивацию;

б) Подкормка РПС (раствор питательный серосодержащий) в междурядья в фразе бутонизации 357 л/га ( $\mathrm{N}_{25}$ Кг д. в./га $+\mathrm{S}_{28}$ 
Урожайность и качество зерна яровой твердой пшеницы

\begin{tabular}{|c|c|c|c|c|c|c|c|c|c|}
\hline \multirow[t]{2}{*}{ Показатель } & \multirow{2}{*}{$\begin{array}{c}\text { Аммиачная } \\
\text { селитра N60 } \\
\text { (производ- } \\
\text { ственный } \\
\text { контроль) }\end{array}$} & \multicolumn{2}{|c|}{ KAC-32 } & \multicolumn{2}{|c|}{ KAC-32 + S } & \multicolumn{2}{|c|}{ KАС-32+PПС } & \multicolumn{2}{|c|}{$\begin{array}{c}\text { Без удобрений } \\
\text { (абсолютный } \\
\text { контроль) }\end{array}$} \\
\hline & & Знач. & $\begin{array}{l}\text { Откл. } \\
\text { От исх. }\end{array}$ & Знач. & $\begin{array}{l}\text { Откл. } \\
\text { От исх. }\end{array}$ & Знач. & $\begin{array}{l}\text { Откл. } \\
\text { от исх. }\end{array}$ & Знач. & $\begin{array}{l}\text { Откл. } \\
\text { от исх. }\end{array}$ \\
\hline Урожайность, ц/га & 20,30 & 20,87 & 0,57 & 22,09 & 2,06 & 25,30 & 5,00 & 16,70 & $-3,60$ \\
\hline Влажность, \% & 12,5 & 12,3 & $-0,2$ & 12,7 & 0,2 & 12,4 & $-0,1$ & 12,0 & $-0,5$ \\
\hline ИДК, единица & 92 & 94 & 2 & 93 & 1 & 90 & -2 & 95 & 3 \\
\hline Клейковина, \% & 28,5 & 30,3 & 1,8 & 30,5 & 2,0 & 31 & 2,5 & 26,9 & $-1,6$ \\
\hline Натура зерна, г/л & 779 & 784 & 5 & 782 & 3 & 790 & 11 & 771 & -8 \\
\hline
\end{tabular}

кг д. в./га) опрыскивателем UR 3000 (AMAZONE) с удлинительными шлангами.

6. Без удобрений (Абсолютный контроль).

\section{Результаты}

В соответствии с принятой программой и выполненными полевыми исследованиями по определению влияния жидких серосодержащих минеральных удобрений на базе КАС-32 получены результаты, определяющие наиболее эфффективные варианты по яровой твердой пшенице сорта Марина (табл. 1, рис. 1) и сое сорта Волма (табл. 2, рис. 2).

Яровая твердая пшеница сорта Марина соответствовала 3 классу качества.

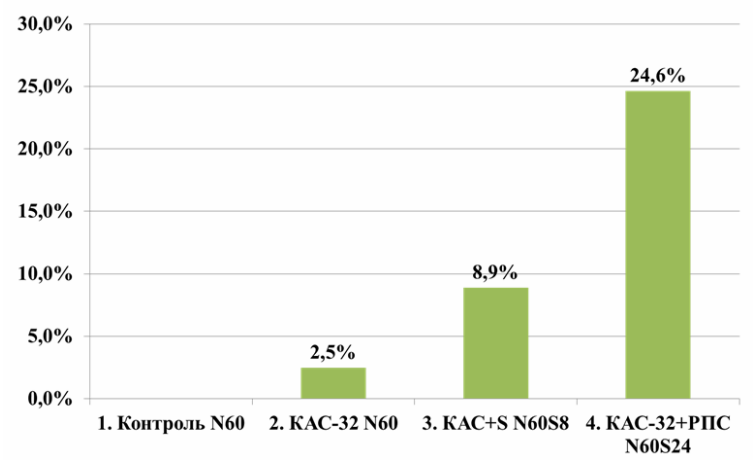

Puc. 1. Прибавка урожайности яровой твердой пшеницы

Проведенными исследованиями установлено, что внесение жидких азотных серосодержащих удобрений питания КАС 32 + сера и РПС на почвах с низким содержанием подвижной серы под яровую твердую пшеницу показало преимущество в сравнении с традиционным внесением аммиачной селитры. Данная технология оправдана и дает прибавку урожайности к контролю на варианте КАС-32 + S - 1,79 ц/га, на варианте КАС-32 + РПС - 5 ц/га. Максимальная урожайность 25,3 ц/га обеспечена от применения КАС-32 + РПС. Качество зерна соответствовало 3 классу, содержание сырой клейковины - 31 \%, натура зерна - 790 г/л. Дополнительная прибыль от применения жидких серосодержащих удобрений на варианте КАС-32 + S составила 5256 руб./га, на варианте КАС32 + РПС - 9702 руб./га по сравнению с контролем.

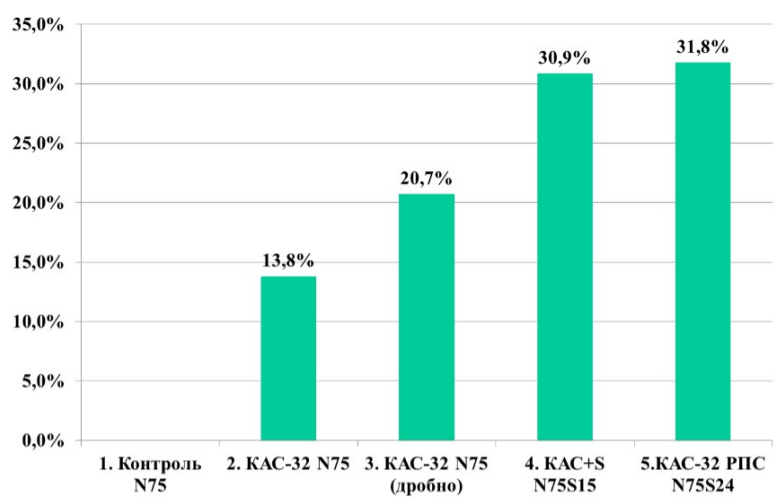

Puc. 2. Прибавка урожайности сои, \%

Таким образом, проведенными исследованиями установлено, что применение серосодержащих удобрений на почвах с низким содержанием серы привело к существенному улучшению в развитии растений сои и формированию более высокой урожайности и качества по сравнению с внесением аммиачной селитры. При этом установлена высокая отзывчивость сои на жидкие азотные (КАС - 32) и жидкие азотосеросодержащие удобрения (КАС - 32 + Сера, КАС - 32 + РПС), которые способствовали увеличению высоты растений в фазе налива семян на 6-8 \% по сравнению с контролем (аммиачная селитра), а также увеличению бобов и семян. Максимальный эффект по урожайности получен при внесении удобрения КАС-32 + РПС, урожайность, по сравнению с контролем, увеличилась на 6,9 ц/га или на $31 \%$. Сбалансированность питания сои азотом и серой имело большее значение, чем одностороннее применение аммиачной селитры.

С учетом мировых тенденций и многолетнего отечественного научнопроизводственного опыта по эффективному применению жидких минеральных удобрений КАС-32, ЖКУ, аммиачная вода и др. все больший спрос возникает у аграриев как к новым технологиям по внесению 
Таблица 2

Урожай и качество сои сорта Волма в опытах с различными вариантами удобрений

\begin{tabular}{|c|c|c|c|c|c|c|c|c|c|c|c|}
\hline \multirow[t]{2}{*}{ Показатель } & \multirow{2}{*}{$\begin{array}{c}\text { Аммиачная } \\
\text { селитра N } \\
\text { (производ- } \\
\text { ственный } \\
\text { контроль) }\end{array}$} & \multicolumn{2}{|c|}{$\begin{array}{c}\text { КАС-32 од- } \\
\text { норазовое } \\
\text { внесение }\end{array}$} & \multicolumn{2}{|c|}{$\begin{array}{c}\text { КАС-32 } \\
\text { дробное } \\
\text { внесение }\end{array}$} & \multicolumn{2}{|c|}{$\begin{array}{c}\text { КАС-32 + S } \\
\text { одноразовое } \\
\text { внесение }\end{array}$} & \multicolumn{2}{|c|}{$\begin{array}{c}\text { КАС-32+РПС } \\
\text { N75+S28 } \\
\text { дробное } \\
\text { внесение }\end{array}$} & \multicolumn{2}{|c|}{$\begin{array}{c}\text { Без } \\
\text { удобрений } \\
\text { (абсолютный } \\
\text { контроль) }\end{array}$} \\
\hline & & знач. & \begin{tabular}{|c|} 
откл. \\
от исх.
\end{tabular} & знач. & \begin{tabular}{|c|} 
Откл. \\
от исх.
\end{tabular} & знач. & $\begin{array}{c}\text { откл. } \\
\text { от исх. }\end{array}$ & знач. & $\begin{array}{c}\text { откл. } \\
\text { от исх. }\end{array}$ & знач. & $\begin{array}{c}\text { Откл. } \\
\text { от исх. }\end{array}$ \\
\hline \multicolumn{12}{|c|}{ Урожайность, ц/га } \\
\hline В опыте & 21,7 & 24,7 & 3,0 & 26,2 & 4,7 & 28,4 & 6,2 & 28,6 & 6,9 & 12,0 & $-9,7$ \\
\hline $\begin{array}{l}\text { По Самар- } \\
\text { ской области }\end{array}$ & 16,5 & 16,5 & 0 & 16,5 & 0 & 16,5 & 0 & 16,5 & 0 & 16,5 & 0 \\
\hline $\begin{array}{l}\text { Уборочная } \\
\text { влажность, \% }\end{array}$ & 8,0 & 7,5 & $-0,5$ & 8,4 & 0,4 & 7,9 & $-0,1$ & 8,2 & 0,2 & 8,0 & 0 \\
\hline $\begin{array}{l}\text { Белок на } \\
\text { АСВ, \% }\end{array}$ & 34,7 & 41,0 & 6,3 & 37,9 & 3,2 & 42,8 & 8,1 & 40,4 & 5,7 & 31,2 & $-2,5$ \\
\hline $\begin{array}{l}\text { Содержание } \\
\text { жира, \% }\end{array}$ & 19,4 & 16,1 & $-3,3$ & 17,2 & $-2,2$ & 17,2 & $-2,2$ & 15,9 & $-3,5$ & 14,8 & $-4,6$ \\
\hline
\end{tabular}

жидких удобрений, так и к соответствующей технике по их внесению. Большую и разнообразную номенклатуру сельхозмашин и специального оборудования для внесения жидких удобрений по различным технологиям выпускает одно из ведущих сельхозмашиностроительных предприятий в России по прицепной технике - АО «Евротехника» (г. Самара) немецкой компании «AMAZONEN-Werke» (Германия) [1-9]. Поэтому эфффективность жидких азотных и новых перспективных азотосеросодержащих минеральных удобрений, как и других видов удобрений [2-4, 8, 10], производимых ПАО «КуйбышевАзот» исследовалась с помощью технико-технологического комплекса $\mathrm{AO}$ «Евротехника» на различных сельскохозяйственных культурах. ФГОУ ВО Самарский государственный аграрный университет более 20 лет испытывает эту технику в зоне Поволжья, что позволило рекомендовать АПК Поволжья и Российской Федерации в целом наиболее эффективные комплексы машин. При совместных исследованиях были выявлены некоторые принципиальные отличия в конструкциях немецких машин от традиционных российских для общепринятых технологий с учетом отличающихся климатических условий по увлажнению. В частности, были сделаны рекомендации, которые были учтены в сельхозмашинах для Российского АПК: по внесению удобрений одновременно с посевом, по преимущественному внутрипочвенному внесению всех видов удобрений как в твердой, так и в жидкой формах и т. д.

Для листовой обработки посевов растений агропредприятиям предлагается широкий выбор опрыскивателей компании AMAZONE [10] с распределением жидких удобрений через многоструйные крупнокапельные форсунки (с тремя, пятью, или семью отверстиями) или язычковые форсунки с плоским факелом распыла (FD) и обычные «мелкокапельные» форсунки при обработке растений КАС в растворе (концентрация КАС - 5 \%). Для внекорневых подкормок растений штанги Super-S опрыскивателей AMAZONE оборудуются отдельным комплектом навесных удлинительных шлангов (рис. Зв), обеспечивающих внесение удобрений в любой фазе развития без нанесения «ожогов» сельхозкультурам концентрированным КАС с наконечниками с одним отверстием при расстановке удлинительных шлангов через 0,25 м и с пятью отверстиями для перекрытия при расстановке шлангов через 0,5 м. Навесные шланги используются для безопасного внесения жидких удобрений. Грузы стабилизируют колебания шлангов в обрабатываемых культурах.

Вся сельхозпродукция на опытных полях Самарской государственной сельскохозяйственной академии производится по технологии «MINI-TILL», главным образом, агрегатами и комплексами машин немецкой компании AMAZONENWerke, произведенными на предприятии АО «Евротехника» (г. Самара, Россия): обработка почвы дисковыми боронами CATROS, посев сеялками DMC, внесение жидких удобрений - опрыскивателями AMAZONE с удлинительными шлангами и крупнокапельными форсунками (рис. 3 а, б, в) и т. д.

\section{Заключение}

Проводимые Самарским государственным аграрным университетом совместные с ПАО «КуйбышевАзот» исследования по изучению эффективности различных удобрений на зерновых и зернобобовых культурах по технологии «MINI-TILL» с использованием сельхозтехники $\mathrm{AO}$ «Евротехника» (г. Самара) немецкой машиностроительной 

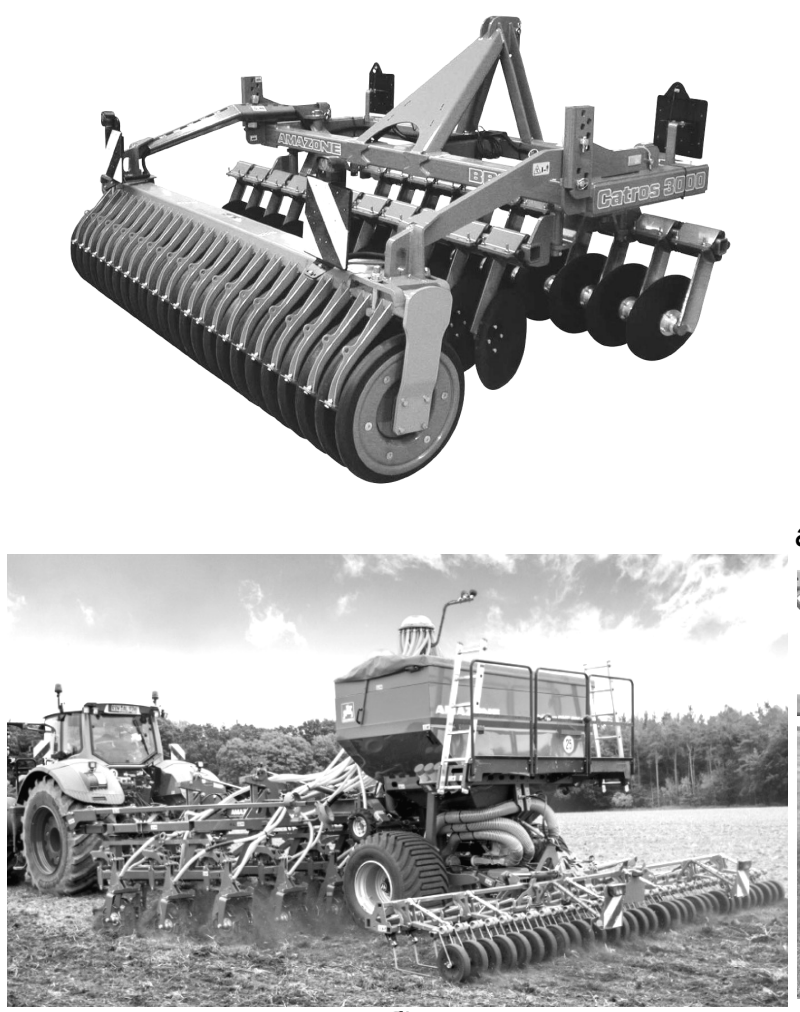

б)

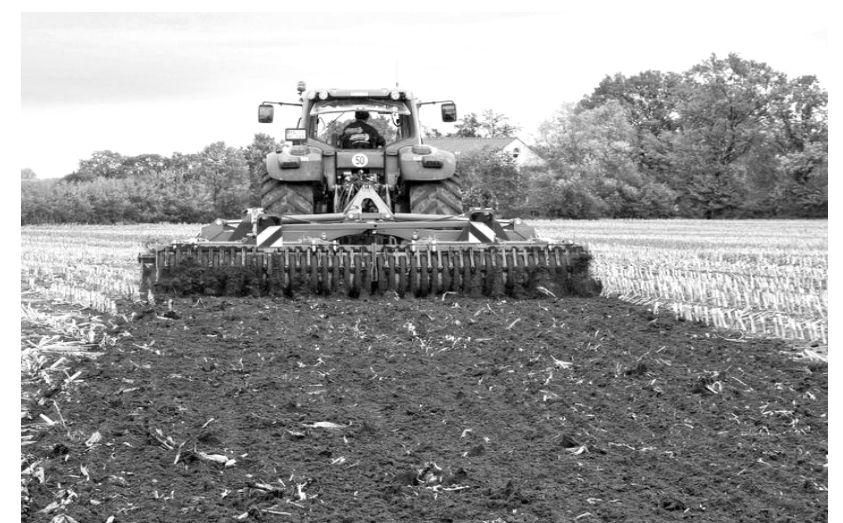

a)

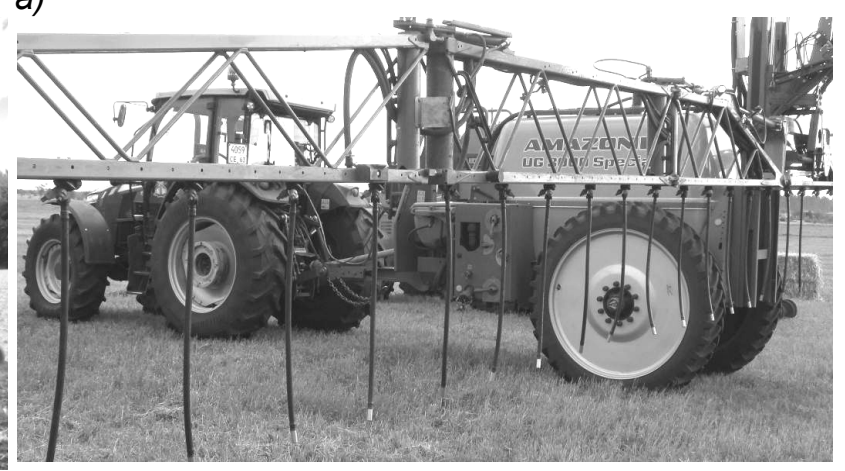

в)

Puc. 3. Сельскохозяйственные агрегаты и комплексы компании «AMAZONEN-Werke» AO «Евротехника» (е. Самара), используемые в технологии MINI-TILL в опытах:

а) дисковая борона Catros, б) сеялка прямого посева DMC, в) опрыскиватель Amazone, оборудованный дополнительными шлангами удлинителями

компании «AMAZONEN-Werke», показывают значительное преимущество жидких минеральных азотных и азотосеросодержащих удобрений на базе КАС-32 в сравнении с широко распространенными твердыми азотными минеральными удобрениями - аммиачная селитра. Особенно большое данное преимущество по урожайности и качеству продукции было получено в засушливых условиях 2018 года при недостатке влаги, что важно использовать в зонах рискованного земледелия - практически все Поволжье и другие аналогичные по погодным условиям регионы.

\section{Лuтература}

1. Милюткин, В.А. Высокоэффективная техника для энерго-, влаго-, ресурсосберегающих мировых технологий Mini-Till, No-Till в системе точного земледелия России: монографияя / В. А. Милюткин, В. Э. Буксман, М. А. Канаев. - Кинель: РИО Самарской ГСХА. - 2018. - 182 с.

2. Милюткин, В. А. Технико-агрохимическое обеспечение повышения урожайности и качества сельхозпродукции внесением жидких минеральных удобрений / В. А. Милюткин, В. Э. Буксман // Ресурсосберегающие технологии и технические средства для производства продукции растениеводства и животноводства: сборник статей IV Международной научно-практической конфреренции. - Пенза: РИО ПГАУ, 2018. - С. 122-127.

3. Милюткин, В.А. Машины и оборудование компании «AMAZONEN-Werke» для внесения жидких минеральных удобрений по различным технологиям / В. А. Милюткин, В. Э. Буксман, Н. Г. Длужевский // Достижения техники и технологий в АПК: материалы Международной научнопрактической конференции, посвященной памяти Почетного работника высшего образования, Академика PAE, доктора технических наук, профессора Владимира Григорьевича Артемьева. Ульяновск: Ульяновский ГАУ, 2018. - С. 176-184.

4. Милюткин, В. А. Инновационные технические решения для внесения жидких и твердых минеральных удобрений одновременно с посевом / В. А. Милюткин, В. Э. Буксман // Техника и оборудование для села. - 2018. - № 10. - С. 10-12.

5. Формирование рационального состава наиболее эффективных разбрасывателей минеральных удобрений для агропредприятий / В. А. Милюткин, М. А. Канаев, В. Э. Буксман [и др.] // Известия Оренбургского государственного аграрного университета. - 2017. - № 6. - С. 111-114. 
6. Милюткин, В. А. Внутрипочвенное внесение удобрений агрегатом X TENDER с культиватором CENIUS при высокоэффективном влагонакоплением / В. А. Милюткин, В. Э. Буксман // Аграрная наука сельскому хозяйству: сборник статей международной научно-практической конференции. - Алтайский государственный аграрный университет, 2017. - С. 41-43.

7. Милюткин, В. А. Совершенствование технических средств для внесения удобрений / В. А. Милюткин, М. А. Канаев // Аграрная наука сельскому хозяйству: сборник статей международной научно-практической конференции. - Алтайский государственный аграрный университет, 2017. C. 36-37.

8. Милюткин, В. А. Повышение эффективности опрыскивателей для внесения жидких минеральных удобрений / В. А. Милюткин, В. Э. Буксман // Известия Оренбургского государственного аграрного университета. - 2018. - № 1(69). - С. 119-122.

9. Милюткин, В.А. Энерго-ресурсо-влагосберегающие технологии в земледелии и рекомендуемые комплексы машин/ В. А. Милюткин, С. А. Толпекин, В. В. Орлов // Стратегические ориентиры инновационного развития АПК в современных экономических условиях: материалы международной научно-практической конференции. - Волгоград: Волгоградский ГАУ, 2016. - С. 232-236.

10. Милюткин, В. А. Приоритетные конструктивные и технологические особенности опрыскивателей для защиты растений при техперевооружении агропредприятий АПК / В. А. Милюткин, С. А. Толпекин, В. Э. Буксман // Нива Поволжья. - 2018. - № 1(46). - С. 97-102.

UDC 631.5

DOI: $10.36461 /$ NP.2019.52.3.012

\section{TECHNICAL AND TECHNOLOGICAL APPLICATION OF LIQUID NITROGEN AND NITROGEN-CONTAINING FERTILIZERS ON THE BASIS OF KAS-32 IN SEEDING CEREAL AND GRAIN LEGUME CROPS}

V. A. Milyutkin, Doctor of Engineering Sciences, Professor,

A. M. Petrov, Candidate of Engineering Sciences, Professor

Federal State Budgetary Educational Institution of Higher Education «Samara State Agrarian University», Russia, t. 8-927-264-41-88, e-mail: oiapp@mail.ru

\section{O. N. Kukharev, Doctor of Engineering Sciences, Professor}

Federal State Budgetary Educational Institution of Higher Education Penza State Agrarian University, Russia, t. 8-927-784-79-11, e-mail: rectorat@pgau.ru

\section{N. G. Dluzhevsky, process engineer, Deputy Director}

Public Joint Stock Company KuibyshevAzot, t. 8-927-784-79-11, e-mail: svrp2@mail.ru

The article presents materials from the laboratory and field studies of the Samara State Agrarian University on the effectiveness of liquid mineral nitrogen and new nitrogen-sulfur fertilizers based on KAS-32 compared with solid fertilizers - ammonium nitrate produced by PAO KuibyshevAzot (Tolyatti, Samara oblast) in the cultivation of cereal crops (durum wheat) and legumes (soybeans) using MINITILL technology provided by the agricultural machinery complex AO Evrotehnika (Samara) of the German company AMAZONEN-Werke (Germany). Objective: to determine the effectiveness of nitrogen liquid mineral fertilizers produced by PAO KuibyshevAzot and new nitrogen-sulfur fertilizers in comparison with traditional solid mineral fertilizers - ammonium nitrate - with the determination of the optimal doses, methods and time of application, the necessary technical means for various crops, including cereals and legumes. In the dry year of 2018 (the seventh drought year since 1936), fairly high results were obtained in terms of yield and quality of the products when using KAS-32, KAS-32 with sulfur and RPS (sulfur-containing nutritious solution) in comparison with solid mineral fertilizers (ammonia nitrate) when applied by AO Evrotehnika sprayers equipped with large-droplet sprayers and extension hoses for foliar and nonroot (root) dressing of plants.

Keywords: machinery, technologies, MINI-TILL, fertilizers, liquid, solid, application, dressing, yield, quality, grain crop, grain legumes.

\section{References:}

1. Milyutkin, V. A. High-performance equipment for energy, moisture, resource saving world technologies Mini-Till, No-Till in the system of precision farming in Russia: monograph / V. A. Milyutkin, V. E. Buksman, M. A. Kanaev. - Kinel: RIO Samara State Agricultural Academy. - 2018. - 182 p.

2. Milyutkin, V. A. Technical and agrochemical support for increasing the yield and quality of agricultural products by applying liquid mineral fertilizers / V. A. Milyutkin, V. E. Buksman // Resource-saving technologies and technical means for the production of crop and livestock production: collection of articles of the IV International Scientific and Practical Conference. - Penza: RIO PGAU, 2018. - P. 122-127. 
3. Milyutkin, V. A. Machines and equipment of the company AMAZONEN-Werke for applying liquid mineral fertilizers using various technologies / V. A. Milyutkin, V. E. Buksman, N. G. Dluzhevsky // Achievements of engineering and technology in the agro-industrial complex: materials of the International scientific-practical conference dedicated to the memory of the Honorary Worker of Higher Education, Academician of RAE, Doctor of Engineering Sciences, Professor Vladimir Grigoryevich Artemyev. - Ulyanovsk: Ulyanovsk GAU, 2018. - P. 176-184.

4. Milyutkin, V. A. Innovative technical solutions for applying liquid and solid mineral fertilizers simultaneously with sowing / V. A. Milyutkin, V. E. Buksman // Technique and equipment for the village. 2018. - No. 10. - P. 10-12.

5. The formation of the rational composition of the most effective spreaders of mineral fertilizers for agricultural enterprises / V. A. Milyutkin, M. A. Kanaev, V. E. Buksman [et al.] // Bulletin of the Orenburg State Agrarian University. - 2017. - No. 6. - P. 111-114.

6. Milyutkin, V. A. Intrasoil fertilization with X TENDER aggregate with a CENIUS cultivator with highly efficient moisture accumulation / V. A. Milyutkin, V. E. Buksman // Agricultural science to agriculture: a collection of articles of an international scientific and practical conference. - Altai State Agrarian University, 2017. - P. 41-43.

7. Milyutkin, V. A. Improving the technical means for fertilizing / V. A. Milyutkin, M. A. Kanaev // Agricultural science to agriculture: a collection of articles of an international scientific and practical conference. - Altai State Agrarian University, 2017. - P. 36-37.

8. Milyutkin, V. A. Improving the efficiency of sprayers for applying liquid mineral fertilizers / V. A. Milyutkin, V. E. Buksman // Bulletin of the Orenburg State Agrarian University. - 2018. - No. 1 (69). - P. 119-122.

9. Milyutkin, V. A. Energy-resource-moisture-saving technologies in agriculture and recommended machine complexes / V. A. Milyutkin, P. A. Tolpekin, V. V. Orlov // Strategic guidelines for the innovative development of the agro-industrial complex in modern economic conditions: materials of an international scientific and practical conference. - Volgograd: Volgograd State Agrarian University, 2016. P. 232-236.

10. Milyutkin, V. A. Priority design and technological features of sprayers for plant protection during technical re-equipment of agricultural enterprises of the agro-industrial complex / V. A. Milyutkin, P. A. Tolpekin, V. E. Buksman // Volga Region. - 2018. - No. 1 (46). - P. 97-102. 